\section{Challenge-Oriented Behavior Types: A New Explanation}

\author{
Burcu Seher Çalıkoğlu*
}

\begin{tabular}{ll}
\hline Received: & 1 August 2019 \\
Revised: $\quad 26$ November 2019 \\
Accepted: $\quad 24$ December 2019 \\
ISSN: 1307-9298 \\
Copyright @ IEJEE \\
www.iejee.com
\end{tabular}

DOI: $10.26822 /$ iejee.2019257667

\begin{abstract}
The purpose of this study is to broaden theoretical meaning of challenge and attain a place for its practical use in schools. Based on the purpose, a theoretical construct was developed to explain four types of challenge-oriented behavior: (a) creators, (b) choosers, (c) maintainers and (d) avoiders. 634 fifth-, sixth- and seventh-grade students in Istanbul, Turkey, participated in the study. The Challenge-Oriented Behavior Scale and the Challenge-Performance Test were the main instruments. The Challenge-Oriented Behavior Scale scores were subjected to non-hierarchical cluster analyses, which revealed four profiles. To gain ecological validity of the current understanding, an alternative method, reverse-action strategy was developed. The aim was to explain how actual student performance is defined by self-perceived challenge-orientation type. To this respect, the Challenge-Performance Test scores and other factors were examined using path analysis. The findings suggest that demonstrated performance in pursuing challenges arise from past experience, academic achievement, self-perceived challenge-orientation type and age.
\end{abstract}

Keywords: Task, Level, Performance, Difficulty, An Alternative Strategy For Ecological Validity

\section{Introduction}

\section{Redevelopment of the Definition of Challenge}

Great scientists, innovators, explorers, artists and politicians ... Their life stories have been constructed on a similar pattern, which confirms the same sequential consistency between obstacles and victories. An English philosopher William Penn's quote of "no pain, no palm; no throne; no gall, no glory; no cross, no crown" summarizes the conventional idea that 'challenge' evokes thoughts of rigor and difficulty while implying the pleasure of growth (Zakaria \& Yatiml, 2013, p. 268). Difficulty and pleasure punctuated as two fundamental dimensions in the current effort for the defining challenge (Figure 1). Although this clears the air on the surface, to reach deeper meaning there is a lot to be done.

In an academic context, Ormrod (2008) uses 'challenge' to indicate a 'level' at which students believe that they will be successful if they make a sufficient effort. How much of Ormrod's 'belief in success' is required to define a challenging situation? Unlike Ormrod, Malone (1981) approaches the concept of challenge as a 'task' that requires effort and in whose outcome success is not guaranteed. Similarly, Zakaria and Yatiml (2013) emphasize the effect of the sense of uncertainty, which enables the individual to maintain his or her focus on the task.

Berns, McClure, Pagnoni and Montague (2001) observed by using functional magnetic resonance imaging that lack of predictability activate reward-related regions of brain, such as midbrain dopaminergic neurons, denser than the certain preference of reward by the participants. Their study explains why the absence of certainty or predictability provides people may stay on the task. Therefore, in a challenge context, the optimum level for the expectation of success lies between the extremes of certain success and certain failure.

As shown in Figure 1, explanations made by Malone (1981), Ormrod (2008), Berns, McClure, Pagnoni and Montague (2001) and Zakaria and Yatiml (2013) make it salient (a) need to exert an effort and (c) probability/uncertainty of success to include already included qualities of the concept. Although effort is key term for describing challenge, it should be positioned with ability for two reasons. Firstly, an (a) effort only awakens the potential or ability in person. Secondly, if (b) ability is not required, there is nothing left to talk about challenge.

Challenge in the definitions above mostly reflects the "difficulty" side, "pleasure" as a second dimension were mostly de-punctuated. Pleasure is the central emotional state to human thinking and actions (Johnston, 1999; Kringelbach,2009). Pleasure can give us answers for why we choose difficulty or delay hedonistic/instant pleasure for higher-order pleasure. "Csikszentmihalyi and LeFevre (1989) found that many of the most pleasurable moments occur when individuals are in what Csikszentmihalyi (1997) terms a state of flow". "According to the researcher, flow tends to occur when a person faces a clear set of goals that require appropriate responses. Pushing the debate further, he tells the secret of starting a good conversation with someone is to find out what the other person's goals are. Why goals are so important? Use personal imagination, regulates the state of mind (Csikszentmihalyi, 1997), helps to grow more personal meaning in life among all various possibilities.

In the book titled as "The Seven Sources of Pleasure in Life", L'Abate (2011) clearly state that the outcome of no control is chaos. And oppositely, the outcome of control is enjoyment of life.

In an ampliative view of challenge, (d) being consciousness to put a goal and (e) being independent reflects the pleasure side.

(c) Probability or uncertainty of success is the only sub-dimension refers both to difficulty and pleasure. The idea of knowing that being-successful-in-the-end will bring happiness might be satisfying; however at the same time being sure in advance that someone will be successful might also reduce happiness. The reason of the fact that while it arous- 
es an excitement (pleasure), it also marks a point for a person to decide whether leaving the goal he or she set or continuing (difficulty). As a summary, challenge can be re-defined: as a situation that stimulates a person to exert a (d) conscious (a) effort by own (e) free will for the opportunity of an (b) individual progress with (c) uncertainty regarding whether the desired end will be achieved (see Figure 1).

\section{Challenge}

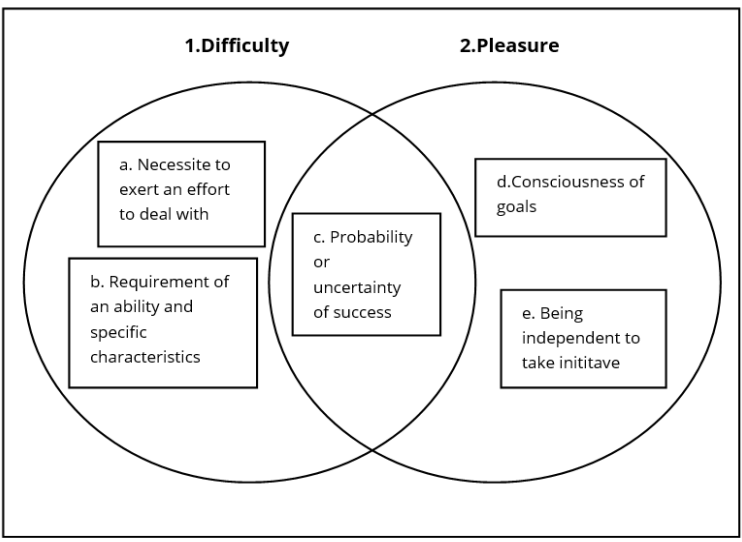

Figure 1. Deconstruction of the concept of challenge

Previous studies

In literature, challenge-oriented behavior is typically grouped into one of two categories: challenge-pursuing and challenge-avoiding behavior (Meyer, Turner, \& Spencer, 1997; Rebolledo-Mendez, du Boulay, \& Luckin, 2006). Challenge pursuers usually become bored with easy tasks and excited about challenging tasks. In contrast, challenge avoiders generally prefer easy tasks (Dweck, 2006; Elliot \& Church, 1997).

In studies by Amabile, Hill, Hennessey, and Tighe (1994); Harter (1981); Koestner, Zuckerman, and Koestner (1987); and Lepper, Corpus, and lyengar (2005), challenge-seeking has long been examined as a sub-dimension of intrinsic motivation. Deci and Ryan (1985) found that highly intrinsically motivated individuals prefer to work at a level above their current performance. However, regardless whether an individual is intrinsically or extrinsically motivated, challenge seekers tend to prefer challenging environments (Brophy, 1983).

Bartle (1996), classified challenge seekers into two categories: achievers and explorers. Achievers are defined as extrinsically motivated. They notice what they must do to win a game so that they can level up. In contrast, explorers are defined as intrinsically motivated because their interest in playing is aroused by curiosity. They do not hurry to finish the game.

Dweck (2006) noted the belief about the changeability of intelligence capacity as a factor that influences challenge-oriented behavior. According to Dweck, individuals with 'fixed mindsets' believe that intelligence is an innate ability. Such individuals assume that ability cannot be changed over time. Thus, they tend to avoid challenging learning environments. They perceive failure as a threat to their self-confidence. In contrast, individuals with 'mastery mindsets' believe that intelligence can be improved with a certain amount of effort. Such individuals prefer challenging environments. In his research, Dweck identified $42 \%$ of his sample as having a fixed mindset and $42 \%$ as having a mastery mindset. The mindset of the remainder of the sample (16\%) could not be defined. These individuals were not included in either group.

Dweck's (2006) uncategorized 16\% suggests that there might be challenge-response types other than challenge seekers and challenge avoiders. Her unidentified category also gave hope to re-formulate challenge-oriented types in this study. It is hypothesized that there are four different challenge-oriented behavior types: (a) creators, (b) choosers, (c) maintainers and (d) avoiders (Figure 2).

As shown in Figure 2, creators create their own challenges when they are not satisfied with the level of challenge in a learning environment. Choosers select challenging learning environments when challenges are offered. However, they are not as active as creators in independently pursuing challenges. Maintainers maintain their own level. They do not engage in easier or more difficult tasks. Such individuals exert the optimum effort required to sustain an acceptable regularity in their lives. They occupy a position between challenge pursuers (i.e., by avoiding failure, loss or harm) and challenge avoiders (by not pursuing achievement). Avoiders avoid challenges. They only expend effort if the task is easy to complete.

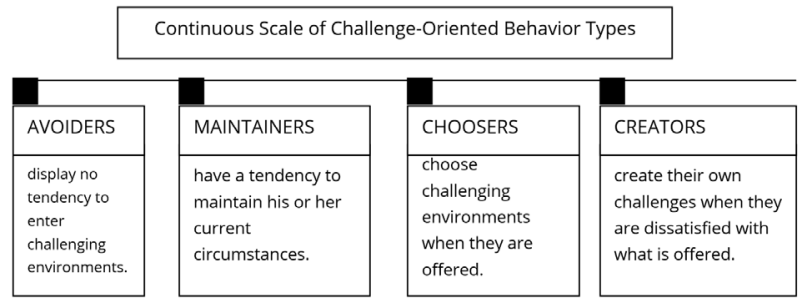

Figure 2. Challenge-oriented behavior types

In previous studies, there was no recognition of 'creators' other than Bartle's (1996) explorers. Although both 'explorer' and 'creator' center on the idea of curiosity (i.e., the desire to learn more about something or someone), they subtly differ in meaning. Explorers select from existing possibilities, as demonstrated in Bartle's (1996) research design. Bartle (1996) considers explorers to involve themselves in acquiring knowledge about the game rather than seeking to finish the game with a high number of points. However, creators create something new, such as developing a novel agent, path or piece of writing. In this context, 'challenge-creator' describes an individual who exerts an intellectual effort to create something that does not yet exist in his or her environment.

The literature strictly separates challenge-avoiding and challenge-pursuing behaviors in a manner that does not enable one to perceive the behavioral gradations that separate these two extremes. This paper assumes that challenge-oriented types of behavior are not restricted to the opposite ends of a range and suggests developmental stages in the classification process, which corresponds to a continuum.

This study aims to construct a theoretical explanation of the types of challenge-oriented behavior through observing students from two viewpoints: (a) how the students perceive themselves with respect to challenges and (b) how the students are actually behave in challenging environments. To this end, two measurement scales were developed to cross-check the data: (a) the Challenge-Oriented Behavior Scale and (b) the Challenge-Performance Test.

\section{Research questions and hypotheses}

This study's purpose was twofold: (a) to validate the challenge-oriented behavior types ('creators', 'selectors', 'maintainers' and 'avoiders') and (b) to explain actual student performance by the self-perceived challenge-oriented type. The two basic questions that this study aims to answer are as follows. (1) Is the classification of the four groups of challenge-oriented profiles valid? (2) What explains the challenge-oriented performance of students?

\section{The significance of the study}

In the literature, challenge-oriented behavior has been considered to be a subcategory of motivation (Harter, 1981; Meyer 
et al., 1997). Consequently, no instrument has been developed to specifically measure the tendencies of individuals in response to challenges. This study focuses on the idea of challenge in detail using two instruments developed by the author. Examining challenge as a discrete concept enabled widening the framework by adding two behavior types to the existing categories of challenge seeker and challenge avoider.

\section{Material and methods}

\section{Participants}

In this study, the participants were 634 students in the fifth, sixth and seventh grades. The participants were selected through cluster sampling. Because this method is less disruptive than the simple random sampling, it is often used in educational research. The groups naturally formed before the research study was implemented (Borg, Gall, \& Gall, 1993). In this study, the schools were chosen randomly. However, the classrooms were not.

The research was conducted in Beşiktaş and neighboring districts in Istanbul. Unfortunately, it was impossible to determine the size of the population of fifth-, sixth- and seventh-grade students in these areas. To understand the density of the population, the demographic data for the counties were reviewed. The number of schools was determined according to the population density for each county. According to 2011-12 demographic statistics, the populations of Beşiktaş, Sarıyer, Şişli and Kağıthane were 186,570, $335,598,274,420$, and 428,755 , respectively (Ministry of $\mathrm{Na}$ tional Education [MoNE], 2011). Figure 3 shows that the selected sample is similar to the target population. The study was conducted in three schools in Kağıthane, two schools in Sarıyer, two schools in Şişli and one school in Beşiktaş.

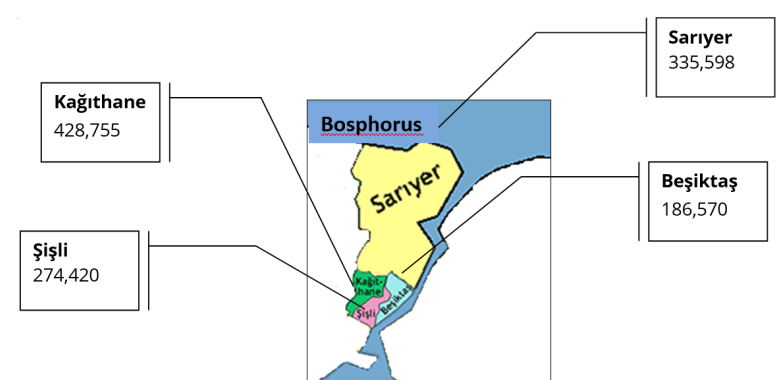

Figure 3. Population of Beşiktaş and surrounding counties in Istanbul

As shown in Table 1, the gender distribution of the sample was 315 males (49.7\%) and 318 females (50.2\%). One student's gender information was missing $(0.2 \%)$. The ages of the participants ranged from 9 to 15 years. Of the participants, 241 were in fifth grade, 234 were in sixth grade and 159 were in seventh grade. Table 1 also shows the socio-economic profiles of the student families. Of the mothers of the participants, 25 (3.9\%) were illiterate, 223 (35.2\%) had graduated from primary school, 148 (23.3\%) had graduated from secondary school, $111(17.5 \%)$ had graduated from high school, $76(12 \%)$ had graduated from university, and 32 $(5 \%)$ had undergone post-graduate study. Nineteen $(3 \%)$ of the participants did not provide the education level of their mothers. Of the fathers of the participants, $4(0.6 \%)$ were illiterate, $170(26.8 \%)$ had graduated from primary school, 193 (30.4\%) had graduated from secondary school, 108 (17\%) had graduated from high school, $96(15.1 \%)$ had graduated from university and 52 (8.2\%) had undergone post-graduate study. Eleven $(1.7 \%)$ of the participants did not provide the education level of their fathers. Of the mothers of the participants, 255 (40.2\%) were employed, $11(1.7 \%)$ were retired and $363(57.3 \%)$ were unemployed. Five $(0.8 \%)$ of the par- ticipants did not provide the employment situation of their mothers. Of the fathers of the participants, 575 (90.7\%) were employed, 29 (4.6\%) were retired and 23 (3.6\%) were unemployed. Seven (1.1\%) of the participants did not provided the employment situation of their fathers. The number of individuals living in the student homes ranged from two to 13.

Table 1. Demographic and socio-economic profiles of participants

\begin{tabular}{lrr}
\hline Demographics & $n$ & $(\%)$ \\
\hline Gender & & \\
\hline Female & 318 & 50.2 \\
\hline Male & 315 & 49.7 \\
\hline Not defined & 1 & 0.2 \\
\hline Total & 634 & 100 \\
\hline
\end{tabular}

Age (years)

\begin{tabular}{lrr}
\hline 9 & 1 & 0.2 \\
\hline 10 & 5 & 0.8 \\
\hline 11 & 211 & 33.3 \\
\hline 12 & 224 & 35.3 \\
\hline 13 & 168 & 26.5 \\
\hline 14 & 22 & 3.5 \\
\hline 15 & 3 & 0.5 \\
\hline Total & 634 & 100
\end{tabular}

\begin{tabular}{lll} 
Total & 634 & 100 \\
\hline Grades & & \\
\hline 5 th & 241 & 38.0 \\
\hline 6 th & 234 & 36.9 \\
\hline 7 th & 159 & 25.1 \\
\hline Total & 634 & 100 \\
\hline District & &
\end{tabular}

\begin{tabular}{|c|c|c|}
\hline Beşiktaş & 146 & 23.0 \\
\hline Kağıthane & 259 & 40.9 \\
\hline Sarıyer & 127 & 20.0 \\
\hline Şişli & 102 & 16.1 \\
\hline Total & 634 & 100 \\
\hline \multicolumn{3}{|c|}{ Mother's Education Level } \\
\hline Illiterate & 25 & 3.9 \\
\hline Primary school & 223 & 35.2 \\
\hline Secondary school & 148 & 23.3 \\
\hline High school & 111 & 17.5 \\
\hline University & 76 & 12.0 \\
\hline Post-graduate & 32 & 5.0 \\
\hline Not defined & 19 & 3.0 \\
\hline \multicolumn{3}{|c|}{ Father's Education Level } \\
\hline Illiterate & 4 & 0.6 \\
\hline Primary school & 170 & 26.8 \\
\hline Secondary school & 193 & 30.4 \\
\hline High school & 108 & 17.0 \\
\hline University & 96 & 15.1 \\
\hline Post-graduate & 52 & 8.2 \\
\hline Not defined & 11 & 1.7 \\
\hline Total & 634 & 100 \\
\hline \multicolumn{3}{|c|}{ Mother's Employment Situation } \\
\hline Employed & 255 & 40.2 \\
\hline Unemployed & 363 & 57.3 \\
\hline Retired & 11 & 1.7 \\
\hline
\end{tabular}


Table 1 (Cont.). Demographic and socio-economic profiles of participants

\begin{tabular}{|c|c|c|}
\hline Demographics & $n$ & (\%) \\
\hline Not defined & 5 & 0.8 \\
\hline Total & 634 & 100 \\
\hline \multicolumn{3}{|c|}{ Father's Employment Situation } \\
\hline Employed & 575 & 90.7 \\
\hline Unemployed & 23 & 3.6 \\
\hline Retired & 29 & 4.6 \\
\hline Not defined & 7 & 1.1 \\
\hline Total & 634 & 100 \\
\hline \multicolumn{3}{|c|}{ Number of family members living at home } \\
\hline 2 & 8 & 1.3 \\
\hline 3 & 68 & 10.7 \\
\hline 4 & 257 & 40.5 \\
\hline 5 & 160 & 25.2 \\
\hline 6 & 77 & 12.1 \\
\hline 7 & 17 & 2.7 \\
\hline 8 & 23 & 3.6 \\
\hline 9 & 10 & 1.6 \\
\hline 10 & 9 & 1.4 \\
\hline 13 & 1 & 0.2 \\
\hline Not defined & 4 & 0.6 \\
\hline Total & 634 & 100 \\
\hline
\end{tabular}

\section{Instruments}

\section{Demographic questionnaire}

The author developed the questionnaire to collect data on the age, gender, school achievements and family socio-economic status of the students.

\section{Challenge-Oriented Behavior scale}

The item pool for the questionnaire was based on studies from the literature that included the keywords 'challenge', 'achievement motivation', 'intrinsic motivation', 'extrinsic motivation', 'challenge-seeking' or 'avoiding'. The $28 \times 4$-item draft scale was based on a theory developed by the author (Figure 1). The scale assesses the self-perceived challenge-oriented behavior of the students.

Each item has four response options with no single correct answer (Figure 4). Although no single answer was correct, the students had to select one response for each question. The scores for each response ranged from 1 to 4 points: 1-point scores indicated 'avoiders', 2-point scores indicated 'maintainers'; 3-point scores indicated 'choosers' and 4-point scores indicated 'creators'.

\section{Q. 3}

In exams, I would like to ...

A. be asked to create our own problems to evaluate.

B. be asked questions that are not easily solved.

C. be asked questions that can be solved by most of the students.

D. be asked questions that can be solved by everybody.

\section{Q. 5}

I think that difficult content that is not taught in classes .......................

A. is not that important.

B. is not worth attempting to learn.

C. is worth searching for by myself.

D. can be interesting if someone teaches me it.

Figure 4. Sample items of the Challenge-Oriented Behavior Scale

\section{Content validity}

An expert from the Turkish Language and Literature Department was asked to examine the language and expressions used in the draft scale items. Then, three experts from the Psychological Counseling and Guidance Department were consulted to determine the content validity of the items. These experts were asked two specific questions: For each item, are the choices and questions consistent with the challenge-oriented behavior, and are the items appropriate for fifth-, sixthand seventh-grade students? The average inter-judge reliability was 0.99 . The content validity ratio (CVR) was analyzed for each item, and the average CVR was 0.93 .

When the scale's structure could be explained through cluster analysis, the construct validity of the Challenge-Oriented Behavior Scale was demonstrated.

The normality assumptions of the items were examined. The items exhibited skewness (which ranged from -1.076 to $0.740 ; p=0.00$ ) or kurtosis (which ranged from -1.377 to 0.785 ; $\mathrm{p}=0.00)$.

The reliability of the Challenge-Type Questionnaire was tested using Cronbach's alpha. The 28-item Challenge-Type Questionnaire had a coefficient alpha of 0.83 . The corrected item total correlations were examined to evaluate each item's consistency with the entire scale. Because extracting individual items did not result in any substantial changes in the scale's structure, none of the items were excluded from the draft scale form.

\section{Challenge-Performance Test}

The Challenge-Performance Test included three phases that aimed to measure student choices with respect to challenge level and their responses to the question. The Challenge-Performance Test was developed by the author to observe challenge-related behaviors of students.

For this test, the author provided each student with a sheet of paper on which seven challenge levels were written and from which the students were to choose: the easiest (level 1), very easy (level 2), easy (level 3), average (level 4), difficult (level 5), very difficult (level 6), the most difficult (level 7). The students were asked to choose only one level, on which a task was later to be performed.

Next, each student was provided a card that corresponded to the level the student had previously selected. On each card, scrambled letters appeared. The easiest level displayed three letters, for example, for the fifth grade, 'ilz'. The correct (i.e., unscrambled) answer for 'ilz' was 'zil'. 'Zil' means 'bell' in Turkish (Figure 5). With each higher level, the number of letters increased. The hardest level had nine letters, such as, for the sixth grade, 'rsreöfpo'. The correct answer for 'rsreöfpo' was 'profesör', which means professor in Turkish.

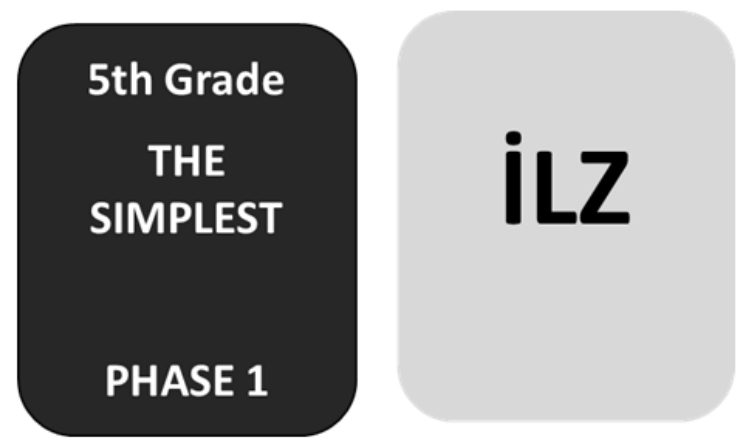

Figure 5. A Card Sample for Challenge Performance Test 
The students were asked to use the letters to form only one correct word within two minutes. After two minutes, the cards were collected, and the students were asked to choose a level for a new word task. This procedure was repeated a total of three times. For each section, there were seven levels. A total of 63 words were used for all of the students.

\section{Face Validity}

Face validity is originated in the idea of Moiser's (1947) "a test should not only be valid, but it should also appear valid." (p. 192, 1947). Within the context of this study, the main question match up to the face validity of Challenge Performance Test was if the test reflects the current understanding of challenge. After Challenge Performance Test was applied, Feedback Questionnaire (Table 2) was asked feelings and opinions to be rated on 4 point rating scale (1: completely disagree, 2: disagree, 3: agree, 4: completely agree) to the volunteers among testees. The reason of why not experts of the field, but testees were asked to participate was: the questions were designed in accordance with students' own challenge level and to get authentic impressions, a person has to experience challenge in a real-setting atmosphere. According to inter-rater agreement of 126 volunteers rates, agreement among seems to be convincing to be valid in the face of volunteers.

Table 2. Inter-rater Agreements for Feedback Questionnaire

\begin{tabular}{lll}
\hline (1) Difficulty & Questions of feedback questionnaire & Agreement \\
\hline $\begin{array}{l}\text { (a) need to exert } \\
\text { an effort }\end{array}$ & $\begin{array}{l}\text { While playing did you feel that you } \\
\text { had to put an effort? }\end{array}$ & .87 \\
\hline $\begin{array}{l}\text { (b) requirement } \\
\text { of ability }\end{array}$ & $\begin{array}{l}\text { Do you think that the more a } \\
\text { person talented the more score a } \\
\text { person can get? }\end{array}$ & .96 \\
\hline $\begin{array}{l}\text { (c) probability/ } \\
\text { uncertainty of } \\
\text { success }\end{array}$ & $\begin{array}{l}\text { Did you feel the uncertainty while } \\
\text { you were about to choose the } \\
\text { level of the card? }\end{array}$ \\
\hline $\begin{array}{l}\text { (d) conscious- } \\
\text { ness of goals }\end{array}$ & $\begin{array}{l}\text { Did you feel that you have to } \\
\text { decide on a goal before you chose }\end{array}$ & .84 \\
\hline $\begin{array}{l}\text { (e) he card? } \\
\text { independence to } \\
\text { take initiative }\end{array}$ & $\begin{array}{l}\text { Did you feel your independence } \\
\text { while choosing your card? }\end{array}$ & .91 \\
\hline
\end{tabular}

\section{Scoring}

The students received two types of scores for this activity: one for the level that they selected, the other for the result of the task. That is, if a student succeeded in the task that he or she preferred, the student received a number of points that was twice the level of preference (i.e., $2 x$ the level of the preference). If a student failed at the level that he or she preferred, the student received points only for the level of preference (i.e., $1 \mathrm{x}$ the level of preference).

\section{Procedure}

The required permissions were obtained from the Provincial Directorate for National Education in Istanbul. The principals and teachers of the schools located in Beşiktaş, Şişli, Kağıthane and Sarıyer also granted their permission. The questionnaires were administered to the students in their own classes by the author. The students were informed regarding the aim of the research and how the scale should be answered. They were also informed that their participation was voluntary.

\section{Data analysis}

In the first step of the data analyses, SPSS 21 software was used to characterize the demographic profiles of the sample through descriptive statistics and to sort the types of chal- lenge-related behavior using K-means cluster analysis. The $\mathrm{K}$-means clustering method selects representative $(\mathrm{K})$ objects to obtain a $\mathrm{K}$ cluster for the data set by assigning each remaining object to the nearest representative object (Kaufman \& Rousseeuw, 2005, p. 40). Discriminant analysis and the split-half method have been found useful for obtaining evidence of the validation and stability of clusters. In the second stage of the study, path analyses were performed to explain the challenge-related performances of students according to other factors.

\section{Results}

\section{Results of the first stage}

To apply cluster analysis to the Challenge-Oriented Behavior Scale, the raw scores for each item were first converted into standard z-scores. K-means cluster analysis indicated that the data could be categorized into four challenge-related behavior types: (a) creators, (b) choosers, (c) maintainers, and (d) avoiders. Table 2 lists the means, standard deviations and z-mean scores for each cluster. As the hypothesis of the study posited, the creators had higher scores than the other types. The choosers had higher scores than the maintainers and avoiders but lower scores than the creators. The maintainers had higher scores than the avoiders but lower scores than the creators and the choosers. Finally, the avoiders had lower scores than the other three types. To obtain evidence of the stability of the clusters, the sample was randomly divided into two halves, and the K-means cluster analysis was repeated for each. The correlation coefficient for the two halves was .885, which indicated that each half of the sample had a similar structure.

Using discriminant analysis, the groups determined via $\mathrm{K}$-means cluster analysis were compared in terms of the following variables: total scores of the Challenge-Oriented Behavior Scale, the presence of a study room at home, mother's education level, father's education level, mother's employment situation and father's employment situation. These factors were not included either in the K-means cluster analysis or path analysis process. The following assumptions of discriminant analysis were tested in turn. (a) Homogeneity of variance: Box's M Test was statistically non-significant $(p=.088)$, which indicated that the variances among the group variables were the same across levels of predictors. (b) Multicollinearity: The variables used in the discriminant analysis were less than 0.70 , which indicated multicollinearity. (c) Normality: The Kolmogorov-Smirnov test was used to analyze the variables 'the presence of a study room at home', 'mother's education level', 'father's education level' 'mother's employment situation' and father's employment situation'. The $p$ values were less than .00 , which indicated that the number of cases at each level was not equal. The ratio of the statistical value of skewness to the standard error of the Challenge-Oriented Behavior Scale scores was between -2 and +2 . The variables used in the discriminant analysis were normally distributed. The assumptions of homogeneity of variance, multicollinearity and normality were found to be acceptable.

A canonical correlation of .916 accounted for $83 \%$ of the variance. An eigenvalue of 5.235 indicated that the clusters were well discriminated. A Wilks's lambda of .153 was found to be significant at the .000001 level. Figure 6 shows that the clusters presented in the study's hypothesis were validated.

\section{Results of the second stage}

In the study's second part, a systematic analytical approach was used to test the relationships between student challenge acceptance and the variables included in the model (Figure 7). Four central considerations explained challenge-based performance: (a) past experience, (b) academic 
achievement, (c) self-perceived challenge-oriented behavior type and (d) age.

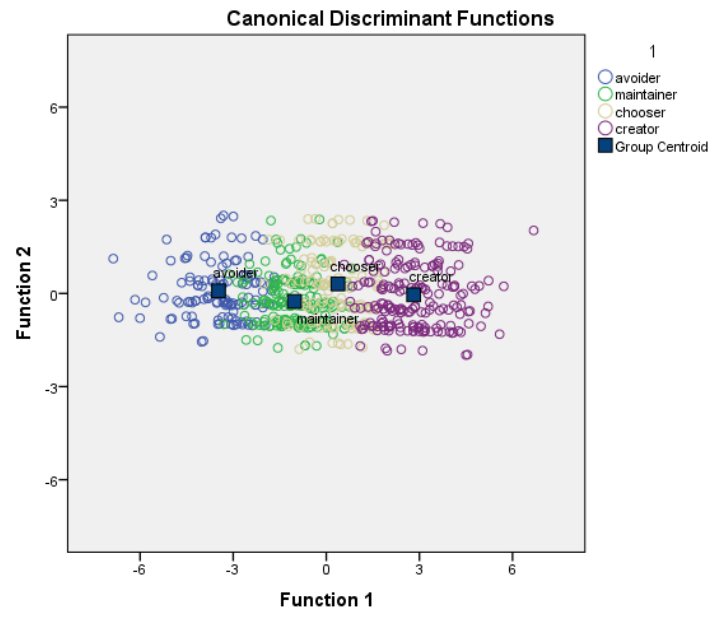

Figure 6. Four clusters explained by the variables 'total scores on the Challenge-Oriented Behavior Scale', 'the presence of a study room at home', 'mother's education level', 'father's education level', 'mother's employment situation' and 'father's employment situation' based on discriminant analysis

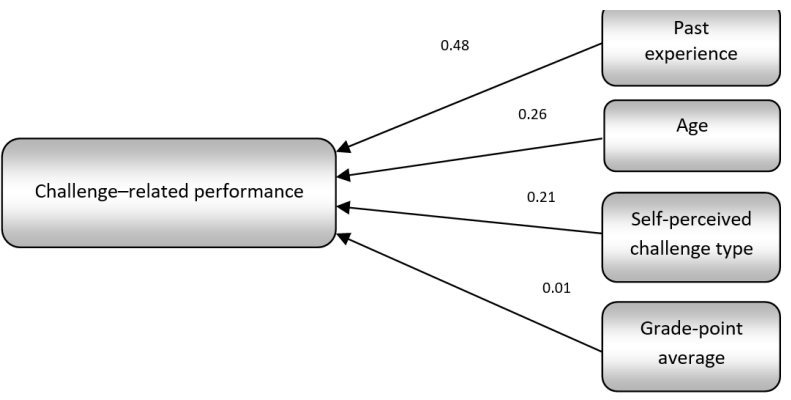

Figure 7. Path model that explains challenge-related performance by past experience, academic achievement, self-perceived challenge-oriented behavior type and age

The results indicate that past experience had the greatest effect on the challenge performances of the students $\left(b_{P E}=7.22\right.$ $z=14.86 ; S E=.48 ; p<.001)$. The second largest influence on the student challenge performance was age $(b=1.281 ; z=4.84$ $S E=.264 ; p<.001)$. The third largest influence on the student challenge performance was perceived challenge-oriented behavior type $\left(b_{P C T}=1.170 ; z=5.06 ; S E=0.231 ; p<.001\right)$. Student grades had the smallest effect on the challenge performance $\left(b_{\text {grade }}=.165 ; z=10.779 ; S E=.015 ; p<.001\right)$.

\section{Discussion}

From the results of the first part of the study, four challenge-oriented profiles emerged: creators, choosers, maintainers and avoiders. As indicated in the introduction, creators not only choose challenging environments but create their own challenges when the level of challenge of tasks is insufficient. Choosers select challenges when they are offered by an authority. Maintainers do not exert more or less effort. Instead, they maintain their pre-established level of challenge. Avoiders do not expend any substantial effort to achieve.

In accord with this study's theoretical basis, the graphical representation of the results obtained by discriminant analyses (Figure 4) reveals that the four clusters represent four different patterns according to the variables 'the presence of a study room at home', 'mother's education level', 'father's education level', 'mother's employment situation' and 'father's employment situation'. Numerous studies demonstrate that socio-economic status and parental education levels prepare the way for children's achievements (Dahl \& Lochner, 2005; Davis-Kean, 2005; Hardas, 2011; Mayer, 2002). As in the flow theory of Csikszentmihalyi (1997) improvement requires challenge. Thus, students with educationally unqualified parents and a disadvantaged economic status lack the support to pursue challenges for their own development.

This study's second part examined the challenge-oriented performances of the students. The results indicate that (a) past experience, (b) academic achievement, (c) self-perceived challenge-oriented behavior type, and (d) age explained these performances. Additionally, path analysis supported the existence of the four challenge-oriented behavior types postulated by the author. The self-perceived challenge-oriented behavior type was one variable that explained the actual challenge-oriented performance of the students. Although the tasks used in Challenge-Oriented Behavior Scale and Challenge-Performance Test differed in terms of particularity and generality, the findings demonstrated that self-perceived behavior in a general sense (Challenge-Oriented Behavior Scale) has an effect on a specific activity (Challenge-Performance Test).

The other factors that explain the challenge-oriented performances of the participants are discussed below:

Past experience: As mentioned in the method section, the Challenge-Performance Test included three stages. At each stage, the students had to select a level, and their prior experience directly affected the next two choices of the students. Typically, the students who experienced success in their first attempt continued to select challenging levels (Figure 5). The study's findings support the knowledge that past experience plays the most important role in shaping an individual's challenge-related behavior. Studies that compared previous achievement experiences with future success have found that past experience is a sound factor that determines the subsequent performances of students (Eskew \& Faley, 1988).

Academic achievement: Grades also played a role in shaping challenge-oriented behavior in an academic context (Figure 6). Students who lacked favorable school-related experiences were more likely to avoid challenges. Although the Challenge-Performance Test is a game-like activity, the students who participated in the study might have perceived that the task concerned school learning because the test was administered at school.

Age: In the Challenge-Performance Test, the students earned points based on the challenge level that they chose and the answers they provided. Thus, the students who chose level 7 challenges (i.e., the most difficult) and could not answer the question earned fewer points (only 7 points) than the students who chose a level 4 challenge (i.e., neither difficult or easy) and could answer the question ( 8 points). To earn additional points, the students first had to correctly assess what they were capable of. Older students might know themselves better than younger ones and have a better ability to determine their next activity. In line with the results of the present study, metacognition-related studies demonstrate that metacognitive skills improve with age (Flavell, Flavell, \& Green, 2001; Flavell, Green, \& Flavell, 2009; Metcalfe \& Shimamura, 1996).

\section{Conclusions}

In sum, the results of this study demonstrate that challenge-oriented behaviors can be re-defined and more accurately specified. Path analysis provides explanations of challenge-related performance. In addition, it provides conceptual support for the new categorization of challenge-oriented behavior types. In contrast to the previous view which had been offered two distinct non-continuous category (challenge-avoider and challenge-seeker; the current study suggests that there are four 
different challenge-oriented behavior types that are on a continuum scale: (a) creators, (b) choosers, (c) maintainers and (d) avoiders.

These results have significant implications for students in every field of education. The Challenge-Oriented Behavior Scale can be used as a starting point to define the challenge-oriented profiles of students, and such information could be useful when developing interventions to change student choices for the better.

Although the present study demonstrated that chronological age is a significant factor in challenge-oriented behavior among children aged 10, 11 and 12 years, it remains unknown when a certain type of behavior stabilizes. This information might be important for educators, who may wish to change the self-perceived challenge-related profiles of students before they become permanent. This possibility calls attention to the need for future research on developmental aspects of challenge-oriented behaviors. As chronological age increases, does a challenge orientation change from a general characteristic to a discipline-specific one? Special interests might arise as a result of aging, and if a more challenge-oriented behavior type could be acquired before these interests develop, students could apply their habits to a specific subject of interest. In accord with this idea, the question of what types of environment positively influence the challenge-related profiles of students substantially increases in importance. Future research should examine the factors that could encourage the development of challenge-oriented behavior.

This research study was performed based on a new theoretical understanding but without investigation the major concept of motivation. The four introduced conceptual categories are projections of motivation. This theoretical understanding could be extended by relating the four categories to intrinsic and extrinsic motivation types.

The fundamental instrument used in the present study (the Challenge-Oriented Behavior Scale) specifically focuses on academic learning. Consequently, the challenge-orientation profiles of the students might not be generalizable to other areas of their lives. The scale was developed for use with fifth, sixth and seventh graders. More research is necessary before the results can be generalized to children in higher and lower grades.

\section{References}

Amabile, T. M., Hill, K. G., Hennessey, B. A. \& Tighe, E. M. (1994). The work preference inventory: Assessing intrinsic and extrinsic motivational orientations. Journal of Personality and Social Psychology, 66, 950-967.

Bartle, R. (1996). Hearts, clubs, diamonds, spades: Players who suit MUDs. Journal of MUD Research, 1(1), 19.

Borg, W. R., Gall, J. P., \& Gall, M. D. (1993). Applying educational research: A practical guide. (3rd ed.). New York, NY: Longman Publishing Group.

Brophy, J. (1983). Conceptualizing student motivation. Educational Psychologist, 18, 200-215.

Csikszentmihalyi, M. (1997). Finding flow: The psychology of engagement with everyday life. Park Avenue South, NY: Basic Books.

Csikszentmihalyi, M., \& LeFevre, J. (1989). Optimal experience in work and leisure. Journal of personality and social psychology, 56(5), 815.

Dahl, G. B., \& Lochner, L. (2005). The impact of family income on child achievement. Working paper 11279. Cambridge, MA: National Bureau of Economic Research. Retrieved from http://www.nber.org/papers/ w11279

Davis-Kean, P. E. (2005). The influence of parent education and family income on child achievement: The indirect role of parental expectations and the home environment. Journal of Family Psychology, 19, 294-304.

Deci, E. L., \& Ryan, R. M. (1985). Intrinsic motivation and self-determination in human behaviour. New York, NY: Plenum Press.

Dweck, C. (2006). Mindset: The new psychology of success. New York, NY: Random House.

Elliot, E. S., \& Church, M. A. (1997). A hierarchal model of approach and avoidance achievement motivation. Journal of Personality and Social Psychology, 72, 218232.

Eskew, R. K., \& Faley, R. H. (1988). Some determinants of student performance in the first college-level financial accounting course. The Accounting Review, 63, 133147.

Flavell, J. H., Flavell, E. R., \& Green, F. L. (2001). Development of children's understanding of connections between thinking and feeling. Psychological Science, 12, 430432.

Flavell, J. H., Green, F. L., \& Flavell, E. R. (2009). Development of children's awareness of their own thoughts. Journal of Cognition and Development, 1, 97-112.

Hardas, D. (2011). Families' social backgrounds matter: socio-economic factors, home learning and young children's language, literacy and social outcomes. British Educational Research Journal, 37, 893-914.

Harter, S. (1981). A new self-report scale of intrinsic versus extrinsic orientation in the classroom: Motivational and informational components. Developmental Psychology, 17, 300-312.

Johnston, V. S. (1999). Why we feel: The science of human emotions. Perseus Publishing.

Kaufman, L., \& Rousseeuw, P. J. (2005). Finding groups in data: An introduction to cluster analysis. Hoboken, NJ: John Wiley \& Sons.

Koestner, R. Zuckerman, M., \& Koestner, J. (1987). Praise, involvement, and intrinsic motivation. Journal of Personality and Social Psychology, 53, 383-390.

Kringelbach, M. L. (2009). The pleasure center: trust your animal instincts. Oxford University Press.

L'Abate, L. (2011). The seven sources of pleasure in life: Making way for the upside in the midst of modern demands. ABC-CLIO.

Lepper, M. R., Corpus, J. H., \& Iyengar, S. S. (2005). Intrinsic and extrinsic motivational orientations in the classroom: Age differences and academic correlates. Journal of Educational Psychology, 97, 184-196.

Malone, T. W. (1981). Toward a theory of intrinsically motivating instruction. Cognitive Science, 5, 333-369.

Mayer, S. E. (2002). The influence of parental income on 
children's outcomes. Wellington, New Zealand: Knowledge Management Group, Ministry of Social Development. Retrieved from http://mpsym.co.uk/images/ influence-of-parental-income\%20on\%20chi.pdf

Metcalfe, J., \& Shimamura, A. P. (1996). Metacognition; Knowing about knowing. Cambridge, MA: MIT Press.

Ministry of National Education (MoNE) (2011). 2011-2012 Eğitim-Öğretim Yılına Ait İstatistikleri [National Education Statistics, Formal Education 2011/2012]. Retrieved from http://istanbul.meb.gov.tr/www/istanbul-il-milli-egitim-mudurlugu-egitim-istatistikleri/icerik/329

Meyer, D. K., Turner, J. C., \& Spences, C. A. (1997). Challenge in a mathematics classroom: Students' motivation and strategies in project-based learning. Elementary School Journal, 97, 501-521.

Merriam-Webster Online. Dictionary and thesaurus. Retrieved from http://www.merriam-webster.com/

Mosier, C. I. (1947). A critical examination of the concepts of face validity. Educational and Psychological Measurement, 7(2), 191-205.

Ormrod, J. (2008). Educational Psychology: Developing Learners (6th ed.). Pearson: Columbus, Ohio

Rebolledo-Mendez, G., Du Boulay, B., \& Luckin, R. (2006, January). Motivating the learner: an empirical evaluation. In Intelligent Tutoring Systems (pp. 545-554). Springer Berlin Heidelberg

Zakaria, N. Z., \& Yatiml, M. H. M. (2013). Measuring effectiveness of challenge characteristic in mobile education game: A review of literature. Paper presented at the World Conference on Integration of Knowledge, Langkawi, Malaysia. 